\title{
Cross-sectional studies of effects of Covid-19 containment measures on children's mental health through a gender lens
}

\section{Silvia Exenberger ( $\sim$ silvia.exenberger-vanham@i-med.ac.at)}

Medical University of Innsbruck: Medizinische Universitat Innsbruck https://orcid.org/0000-0002-62563058

\section{Anna Wenter}

University of Innsbruck: Universitat Innsbruck

\section{Christina Taferner}

Tirol Kliniken $\mathrm{GmbH}$

\section{Nina Haid-Stecher}

Tirol Kliniken $\mathrm{GmbH}$

\section{Maximilian Schickl}

University of Innsbruck: Universitat Innsbruck

\section{Barbara Juen}

University of Innsbruck: Universitat Innsbruck

\section{Kathrin Sevecke}

Medical University of Innsbruck: Medizinische Universitat Innsbruck

\section{Heidi Siller}

Alpen-Adria University: Alpen-Adria-Universitat Klagenfurt

\section{Research Article}

Keywords: Covid-19, gender, girls and boys, mental health, trauma symptoms

Posted Date: March 2nd, 2022

DOI: https://doi.org/10.21203/rs.3.rs-1227969/v1

License: (c) (i) This work is licensed under a Creative Commons Attribution 4.0 International License. Read Full License 


\section{Abstract}

Background: The Covid-19 pandemic has disrupted the daily life of girls and boys worldwide.

Methods: This online study explored the effects of Covid-19 containment measures on Austrian and Italian children's mental health (threat experience, anxiety, trauma symptoms). Data was collected at three measurement time points (June 2020, December 2020, June 2021) from 558 children (50,2\% girls), and 1.133 adults, who have children aged 7-13. Children and parents reported about the children's mental health.

Results: The findings revealed an inconsistent picture of gender differences and similarities: girls and boys reported a similar amount of threat experience, anxiety and trauma symptoms. Parents also estimated girls' and boys' mental health similarly. Gender differences became apparent when the parents' estimations of girls' and boys' trauma symptoms were compared to children's self-reports. Parents underestimated children's trauma symptoms at all measurement time points.

Conclusions: The results are discussed against the background of socio-constructionist and sociodevelopmental gender theories. Future research should explore the socialisation of girls and boys during a pandemic.

\section{Background}

On March 11, 2020, the World Health Organization (WHO) classified the outbreak of the coronavirus disease (Covid-19) as a pandemic (1). Since then the governments in Austria and Italy (where the present study took place) responded with specific containment measures to keep the virus propagation under control. In Austria, the first national lockdown including physical distancing, movement restriction as well as the closure of non-essential business and gastronomy was ordered on March 16, 2020 (2). Due to the severe outbreak in Northern Italy at that time, the Italian government reacted even before the WHO's declaration that Covid-19 was a pandemic: on March 5, 2020, all schools as well as all childcare-related services and activities were suspended (3). Further lockdown measures were taken in the following days and on March 10, 2020, the first national lockdown was ordered in Italy (4). In the summer of 2020, the Austrian as well as the Italian government relaxed the corona measures, but at the end of summer in both countries stricter measures had to be implemented again $(5,6)$. This resulted in a second national lockdown in Austria on November 17, 2020 (7), and in Italy on November 3, 2020 (8). In Austria as well as in Italy, primary schools remained closed for about 60 instructional days in 2020: Austria ranked eighth, Italy sixth out of 30 countries in terms of school closure days (9). Beginning in spring 2021, the Austrian and Italian governments started to gradually relax the restrictions again $(6,10)$. Until June 2021 , when the third measurement time point of the study took place, there had been 631 deaths related to Covid-19 in North Tyrol (Austria) (11) and 1,175 in South Tyrol (Italy) (12).

\subsection{Effects of corona measures on children}


Studies from all over the world report negative effects of the Covid-19 pandemic and its accompanying containment measures on children's mental health. Systematic reviews and meta-analyses explicitly focusing on children report high levels of anxiety (e.g., 13-15) and trauma symptoms (e.g., 16, 17), in addition to other negative mental health outcomes such as depression and sleep problems. Also many European studies (which are of particular interest for the present study) from children's and parent's perspective outline anxiety as a widespread negative mental health outcome in kindergarten and school children during the corona crisis, e.g., Luijten et al. (18; The Netherlands), Pereira et al. (19; Portugal, United Kingdom, Romania, Spain, and The Netherlands), Pizarro-Ruiz and Ordóñez-Camblor (20; Spain) and Schmidt et al. (21; Austria, Germany, Liechtenstein, and Switzerland). In a German study Rothe et al. (22) found significant changes in emotions and worries from the time before Covid-19 to the time during the pandemic in four groups, namely adults with and without mental health conditions as well as children and adolescents with and without mental health conditions. Regarding Covid-19-virus related worries, Vogel et al. (23) found that German children worried most about their families and were least concerned about themselves. Concerning worries and anxiety, qualitative European studies found similar results: Spanish children reported negative emotional effects such as fear, nervousness, worry, sadness, anger, and boredom (24), Irish families described their children as anxious and high strung during the pandemic (25) and in an Italian sample most children reported mild to severe anxiety during quarantine and being concerned especially about their family members (26). With regard to traumatic effects of the Covid-19 pandemic, Terzioğlu and Büber (27) showed that 20.9\% of 1,059 Turkish children aged 10 to 15 had high trauma scores and trauma scores were significantly higher in families with a low income level as well as in divorced families.

In the European context two studies in large samples which compared data before the pandemic in 2017 with data during the pandemic are available from the United Kingdom (UK; 28$)$ and Germany $(29,30)$. Key findings of the study in the UK showed that the rates of probable mental disorders in 5 to 16 year old children increased from $10.8 \%$ in 2017 to $16.0 \%$ in July 2020 . More than a quarter of the children reported disrupted sleep and one in ten often or always felt lonely (28). Similar results were reported from the COPSY-study (impact of Covid-19 on psychological health; 29, 30), which provides a pre-post comparison of mental health in a German population-based sample (before the pandemic: $N=1,556$; wave $1: N=$ 1,586; wave 2: $N=1,288$ ): in the first wave, two-thirds of the 7- to 17-year-old children and adolescents reported being highly burdened by the Covid-19 pandemic. Mental health problems increased from $9.9 \%$ before the pandemic to $17.8 \%$ during the pandemic and anxiety levels from $14.9-24.1 \%$ (29). In the second wave emotional problems, peer problems, anxiety, depressive symptoms as well as psychosomatic complaints increased significantly (30).

\subsection{Gender differences in mental health during the corona crisis}

Meta-analyses on posttraumatic stress in children and adolescents (e.g., 31, 32) identified female gender as a risk factor, i.e. girls tend to show more trauma symptoms than boys. Research on previous epidemics (e.g., Severe Acute Respiratory Syndrome (SARS), Influenza A virus subtype H1N1) showed 
that gender is a factor influencing perceptions, responses and psychological distress in adults. For example, women were more likely to be emotionally disturbed (33) and reported more posttraumatic stress symptoms than men (33-35). With regard to children, Sprang \& Silman (34) found no gender differences in their posttraumatic stress symptoms (reported by their parents) due to a pandemic disaster with accompanying disease-containment measures. However, concerning the current Covid-19 pandemic meta-analyses on children's mental health consistently found that girls were more likely to experience negative mental health outcomes than boys' (e.g., 13-17). A systematic review by Ma et al. (17) including 23 studies with 57,927 Chinese and Turkish child/adolescent participants showed that female participants and adolescents exhibited a higher prevalence of anxiety and depression compared to male participants and children, respectively (17). Another meta-analysis (15) of 115 articles presenting data on a total of 127,923 children and adolescents notes that in most studies girls reported higher levels of worry, concern and fear regarding Covid-19 as well as more notable declines in general mental health during the pandemic based on retrospective self-report compared with boys (e.g., 36, 37). In the German COPSY-study, girls reported more symptoms than boys with regard to having headaches, stomach aches and feeling low while female gender was also associated with fewer parent-reported mental health problems (emotional symptoms, conduct problems, hyperactivity) except for peer problems (29).

In research on mental health on children it is a commonly accepted practice to obtain information from multiple informants, e.g. children and parents (e.g., 38). Findings on child-parent agreement on symptom estimation show that correlations between children and parents are low to moderate (39). Child characteristics, such as age and gender, have been suggested as potential factors having an impact on child-parent agreement (e.g., 40), but findings regarding gender have been mixed. Some studies found higher agreement between boys and parents than between girls and parents (41), other studies reported that gender has no predictive value (e.g., 42).

\subsection{Gender framework}

The above mentioned meta-analyses (e.g., 15) show that the majority of studies confirm the existence of gender-specific challenges associated with the Covid-19 pandemic. In other words, the pandemic might impact mental health differently by gender. Looking at gender beyond sex (the biological determinant) gender is viewed as an achieved status, i.e. it is constantly created and re-created out of human interaction, and out of social life. West and Zimmerman (43) coined this process with the term "doing gender". Gender is individually and socially experienced, and these social roles might partially explain gender differences (ibid.). According to Ellemers (44) parents might raise and educate children in a way that implicitly teaches them what behaviour is (in)appropriate for girls and boys. Brody and Hall (45) assume that girls and boys acquire gender-related rules for emotion expression as a result of a combination of biologically predispositions and socialisation. In many Western cultures girls and women are believed to be more emotionally intense, i.e. they exhibit greater levels of emotions such as happiness and internalising emotions (e.g., sadness, fear and anxiety) (ibid.). In this study, we refer to gender as we consider any differences and similarities in a socio-constructivist and socio-developmental light compared to a biological perspective. However, we are aware of the mostly used integral perception of 
emotional development, which combines biological, socio-constructivist and social development theories (46).

The present study aims to discover the negative effects of the Covid-19 pandemic measures on girls and boys from North Tyrol (Austria) and South Tyrol (Italy). North and South Tyrol - although belonging to two different countries nowadays - are geographically and historically tightly related territories. Until 1919, South Tyrol had been part of the Austrian Crown (47). With the Treaty of Saint-Germain at the end of World War I the Habsburgian province Tyrol was divided into two halves, the southern part (South Tyrol) being awarded to Italy and the northern part (North Tyrol) remaining with Austria (48). Due to this historical background North and South Tyrol not only share the German language (49; South Tyrol: $69.4 \%$ German, 26.1\% Italian, 4.5\% Ladin (50)) but many other commonalities: a similar racial background, many cultural similarities, similar lifestyles and many customs (48). Today, along with the Autonomous Province of Trento, North and South Tyrol constitute the transboundary European Region Tyrol - South Tyrol - Trentino (47).

The main purpose of this investigation was to explore the impact of corona containment measurements on girls and boys with regard to their self-rated experience of threat, trauma, and anxiety at three measurement times (June 2020, December 2020, June 2021). In addition to the children's selfassessments, adults, who have children between 7 and 13 years (henceforward: parents), also assessed from their perspective the children's experience of threat, trauma and anxiety (at the same time points). Across the three measurement time points differences between self and proxy ratings were also a focus. Specifically, we analysed differences in perceived threat, trauma, and anxiety between (1) girls' and boys' self-ratings, assuming that girls score higher than boys, (2) parents' ratings of girls, and parents' ratings of boys, assuming that parents report a similar amount of symptoms for girls and for boys, (3) girls' and parents' ratings of girls, assuming that parents report less symptoms than girls themselves, and (4) boys' and parents' ratings of boys, assuming that parents report less symptoms than boys themselves.

\section{Methods \\ 2.1 Setting}

The present online study was conducted in North Tyrol (Austria) and South Tyrol (Italy). These two regions, situated in the Alps, were among the European regions most afflicted by Covid-19 during the initial phase of the pandemic since in February 2020 the Paznaun Valley in North Tyrol and the Gardena Valley in South Tyrol - two well-known winter tourism destinations - had turned into high risk areas, i.e. corona hotspots $(51,52)$.

\subsection{Participants}

A total of 558 children aged 7 to 13 , of which $50.2 \%$ were girls and $49.8 \%$ were boys, participated in the study (t1: $n=217$, t2: $n=200$, t3: $n=141)$. The mean age of children was 10.1 years $(S D=1.7)$. In addition, 1,133 parents (t1: $n=258, \mathrm{t} 2: n=471, \mathrm{t} 3: n=404)$ provided information about girls $(n=552$, 
$48.7 \%)$ and boys ( $n=581,51.3 \%$ ), whereof $91.0 \%$ of the participating parents were mothers $(8.0 \%$ fathers, $1.0 \%$ not specified). The children's mean age was 9.6 years $(S D=1.8)$. Further characteristics of this sample including age distribution, gender, region and living situation are presented in Table 1. About half of the sample came from North Tyrol (Austria), the other half came from South Tyrol (Italy). The number of household members in the families ranged from 2 to 6 , with $90.3 \%$ of the sample having between 3 and 5 household members. Eligibility criteria were the place of residence (North or South Tyrol), being proficient of the German language and being cognitively capable to fill out an online questionnaire. Children could participate in the study if they were between 7 and 13 years old, adults if they had children between 7 and 13 years (henceforward parents).

Table 1

Socio-demographic data of the sample 


\begin{tabular}{|c|c|c|c|c|c|c|}
\hline & \multicolumn{2}{|c|}{ Child Self-Report } & \multicolumn{2}{|c|}{ Parent View } & \multicolumn{2}{|l|}{ Total } \\
\hline & $n$ & $\%$ & $n$ & $\%$ & $n$ & $\%$ \\
\hline Sample size & 558 & 33 & 1133 & 67 & 1691 & 100 \\
\hline \multicolumn{7}{|c|}{ Measurement time point } \\
\hline Mar 2020 & 217 & 39 & 258 & 23 & 475 & 28.1 \\
\hline Dec 2020 & 200 & 36 & 471 & 42 & 671 & 39.7 \\
\hline Jun 2021 & 141 & 25 & 404 & 36 & 545 & 32.2 \\
\hline \multicolumn{7}{|l|}{ Child Age } \\
\hline 7 years & 27 & 5 & 190 & 17 & 217 & 12.8 \\
\hline 8 years & 81 & 15 & 173 & 15 & 254 & 15.0 \\
\hline 9 years & 97 & 17 & 186 & 16 & 283 & 16.7 \\
\hline 10 years & 118 & 21 & 199 & 18 & 317 & 18.7 \\
\hline 11 years & 98 & 18 & 157 & 14 & 255 & 15.1 \\
\hline 12 years & 120 & 22 & 179 & 16 & 299 & 17.7 \\
\hline 13 years & 17 & 3 & 49 & 4 & 66 & 3.9 \\
\hline \multicolumn{7}{|l|}{ Gender } \\
\hline Girl & 280 & 50 & 552 & 49 & 832 & 49.2 \\
\hline Boy & 278 & 50 & 581 & 51 & 859 & 50.8 \\
\hline \multicolumn{7}{|l|}{ Region } \\
\hline North Tyrol & 296 & 53 & 604 & 53 & 900 & 53.2 \\
\hline South Tyrol & 261 & 47 & 520 & 46 & 781 & 46.2 \\
\hline \multicolumn{7}{|c|}{ Total number of household members } \\
\hline 2 & 13 & 2 & 35 & 3 & 48 & 2.8 \\
\hline 3 & 98 & 18 & 190 & 17 & 288 & 17.0 \\
\hline 4 & 278 & 50 & 614 & 54 & 892 & 52.7 \\
\hline 5 & 124 & 22 & 225 & 20 & 349 & 20.6 \\
\hline 6 & 45 & 8 & 69 & 6 & 114 & 6.7 \\
\hline
\end{tabular}


The online survey was provided in German since the study was conducted in German speaking areas (North Tyrol in Austria and South Tyrol in Italy). The following standardised and validated German measures were used. The wording of the instructions was adapted to the corona-situation.

\section{Child self-report measures}

Demographic characteristics. The child reported his/her nationality (North Tyrol, Austria / South Tyrol, Italy), age, gender and the number of household members.

Experienced Threat. The child reported his/her experienced threat due to the coronavirus: worry that a family member could fall ill; worry that the child him-/herself could fall ill; worry that a family member could die; worry that the child him-/herself could die.

Child and Adolescent Trauma Screen - Self Report (CATS, German version) (53). This 20-item self-report screens children at risk for PTSD (e.g., "Not wanting to do things you used to do."). It is based on the DSM-5 criteria and therefore measures symptoms of the following four dimensions: re-experiencing, avoidance, negative mood-cognitions and arousal. The items are rated on a 4-point Likert scale that ranges from 0 (never) to 3 (almost always). The total score is computed by summing the items (scale range: $0-60$ ). In a German sample of 117 children and adolescents (7 to 17 years) recruited in two German clinics a Cronbach's alpha coefficient of $a=.90$ for the full scale was found (53). In the present study the internal consistency for the full scale was excellent $(a=.91)$.

Kinder-Angst-Test-III (KAT-III, Form R) [Children-Anxiety-Test-III, form R] (54). This self-report consists of 10 binary items assessing the child's state anxiety (e.g., "I am worried."). It allows children to characterise their experienced anxiety. The 10 items are divided into three subscales: worries, anxiety and helplessness. The total score is computed by summing the items (scale range: $0-10)$. Psychometrics are based on a sample of 1,438 German children ( 6 to 18 years) in stressful situations: internal consistency levels were acceptable to good with Cronbach Alpha coefficients between $a=.77$ and $a=.81$ (54). In the present study the internal consistency for the full scale was good $(a=.88)$.

\section{Parent proxy-report measures}

Demographic characteristics. The parent reported his/her own gender and nationality (North Tyrol, Austria / South Tyrol, Italy) as well as the child's gender, the child's age and the number of household members

Experienced Threat. The parent informed about his/her child's experienced threat due to the coronavirus: worry that a family member could fall ill; worry that the child him-/herself could fall ill; worry that a family member could die; worry that the child him-/herself could die.

Child and Adolescent Trauma Screen - Caregiver Report (CATS, German version) (53). The CATS is a 20item parent report about the child's risk for PTSD (e.g., "Having very negative emotional states (afraid, angry, guilty, ashamed).". It is based on the DSM-5 criteria and therefore measures symptoms of the following four dimensions: re-experiencing, avoidance, negative mood-cognitions and arousal. The items 
are rated on a 4-point Likert scale that ranges from 0 (never) to 3 (almost always). The total score is computed by summing the items (scale range: 0-60). In a German sample comprising 95 caregiverreports for 7-to-17-year-old children and adolescents a Cronbach's alpha coefficient of $a=.88$ for the total score was found (53). In the present study the internal consistency for the full scale was excellent (a $=.92)$.

Subscale "anxious/depressed" of the Child Behavior Checklist (CBCL/6-18R, German version) (55). By filling in the $C B C L / 6-18 R$ (e.g., "Too fearful or anxious.") the parent assesses his/her child's behavioural problems, emotional problems, somatic complaints and social skills on a 3-point Likert scale ranging from 0 (not true) to 2 (very true or often true). The subscale anxious/depressed is computed by summing 13 items (scale range: $0-16$ ). In a field sample of 985 school children (6 to 11 years) Cronbach alpha coefficients of $a=.73$ and $a=.80$, for girls and boys respectively, were found (56). In the present study the internal consistency was good $(a=.86)$.

\subsection{Procedure}

The present investigation was part of a large research project about the medium and long-term impact of the corona crisis on children in North and South Tyrol aged 3 to 12 years. This research project was funded by the Land Tirol (Austria). The online study was conducted by using the software LimeSurvey (57) for the first measurement time point (t1) and CHES (58) for the following measurement time points (t2 and t3).

At $t 1$ (June to August 2020) all schools of the 15 Tyrolean corona hotspots joined the study. The Paznaun Valley, St. Anton and Sölden were the North Tyrolean corona hotspots $(51,59)$ whereas the Gardena Valley was the South Tyrolean corona hotspot (52). In addition, five other South Tyrolean municipalities (Castelrotto, Braies, Villabassa, Corvara and La Valle) were defined as corona hotspots (i.e., municipalities where at the end of May 2020 the ratio of people tested positive (12) to residents (50) was the highest). Via the schools in the corona hotspots, children and parents were invited to report retrospectively about the children's mental health during the first lockdown in March 2020.

At measurement time points two (t2, December 2020/January 2021, second wave) and three ( $\mathrm{t} 3$, June/July 2021, relaxation of corona measures after the third wave) children and parents were recruited via the schools which had participated in $\mathrm{t} 1$. In addition, participants were recruited via North and South Tyrolian media (print media as well as online formats). At $\mathrm{t} 2$ and $\mathrm{t} 3$ children and parents reported about children's actual mental health.

Parents and children gave written informed consent for study participation; for children a child friendly version of informed consent had been elaborated. At any stage of the survey children as well as parents could refuse further participation without giving any reason. In case of psychological problems or questions children and parents could consult the outpatient clinic or the first author (parents) and third author (children) of this study. The ethics committee of the Medical University of Innsbruck approved the study (No.: 1183/2020). The ethical vote of the Medical University of Innsbruck is also valid for the 
German-speaking population of South Tyrol. This was clarified verbally with the president of the South Tyrolean Ethics Committee.

\subsection{Data Analysis}

All data were analysed using $\mathrm{R}$ version 4.1. Descriptive statistics were computed for the sociodemographic characteristics and mental health scales.

Inductive statistics for the comparisons of outcomes between girls and boys (children's self-report) and the parents' views (proxy-report), and between measurement time points were calculated using t-tests. Finally, all subsequent results were converted to effect sizes (Pearson $r$ ) when possible to facilitate results for meta-analyses. Effect sizes can be interpreted as follows: small if $r=.1$ to .3 , medium if $r=.3$ to .5 and large if $r \geq .5$ (60). P-values $\leq .01$ were considered statistically significant (2-sided NHST).

\section{Results}

\subsection{Threat experience, anxiety, and trauma from girls' and boys' perspective and parents' perspectives}

All examined outcomes increased between March 2020 and June 2021. Children reported more anxiety, $r(355)=.29, p<.001$, more trauma, $r(355)=.28, p<.001$, and more threat experience, $r(355)=.15, p=.006$. Parents reported more anxiety, $r(659)=.21, p<.001$, more trauma, $r(655)=.16, p<.001$, and more threat experience, $r(648)=.15, p<.001$ in children, too. Mean scores of girls' and boys' self-reports and the parents' reports on children for the three outcomes threat, trauma, and anxiety are shown separately in Figure 1.

Parents reported fewer trauma symptoms for girls, $r(829)=-.13, p<.001$ and for boys, $r(853)=-.17, p<.001$ than children themselves. Girls, $r(822)=-.03, p=.422$, and boys, $r(849)=.01, p=.826$ reported the same level of threat as parents did about children. Child self-reported anxiety (KAT-III) could not be compared directly to parents' view of children's anxiety (CBCL), because they had been measured with two different scales. A detailed comparison of all four groups (girls' self-report, boys' self-report, parent view of girls, parent view of boys) at the individual measurement points can be seen in Table 2.

The only difference that emerged was when comparing the parents' view with children's self-report in trauma. Parents reported less trauma in girls than girls themselves at each measurement time point, i.e. in March 2020, $r(212)=.23, p<.001$, in December 2020, $r(345)=.15, p=.004$ and in June 2021, $r(262)=.16$, $p=.009$, than girls themselves. Regarding boys, parents reported less trauma in boys in December 2020, $r(317)=.21, p<.001$, and in June $2021, r(271)=.26, p<.001$, than the boys themselves.

Table 2

Differences in parent view and self-report of girls and boys at each measuring time point 


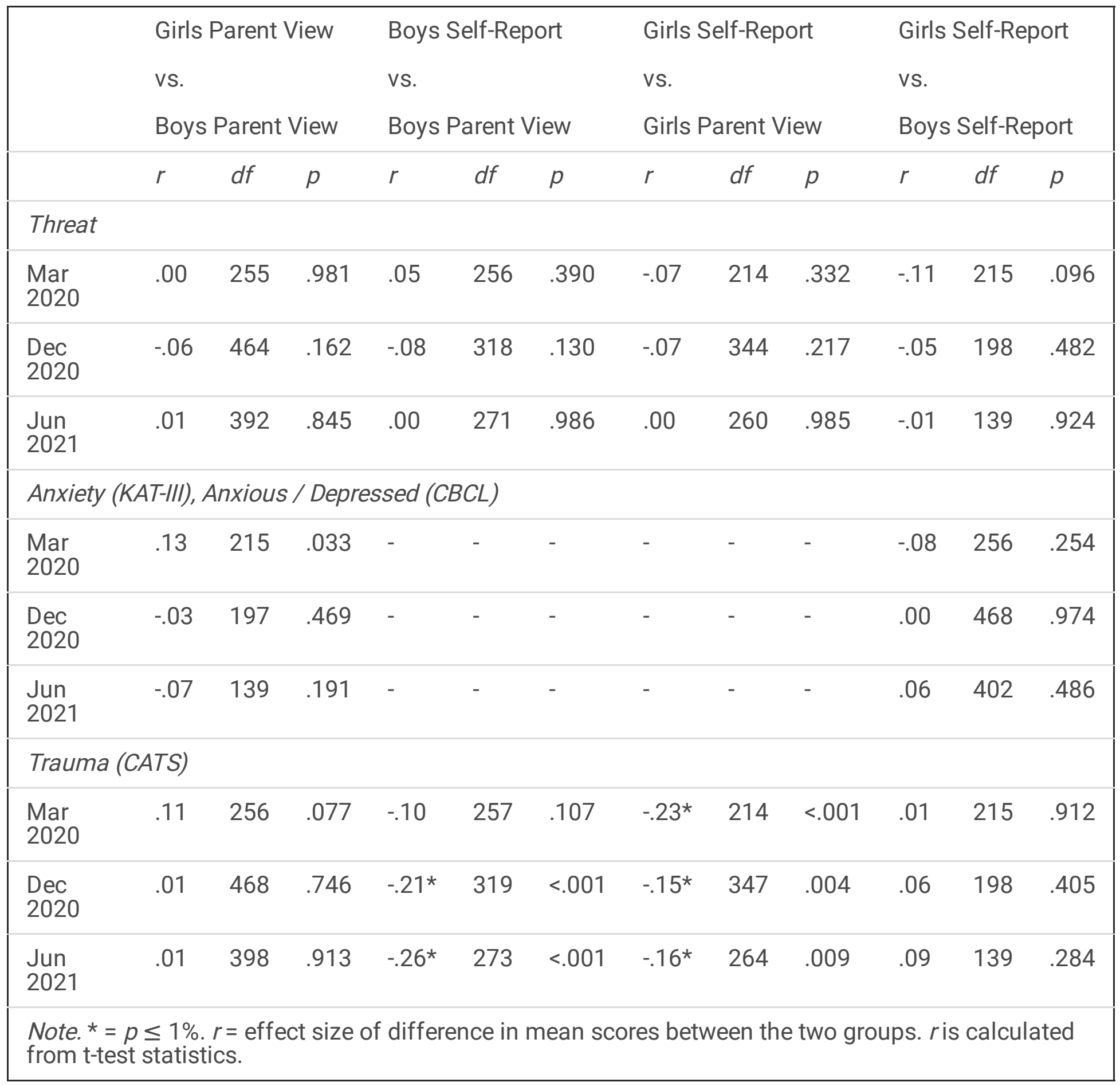

\section{Discussion}

The main objective of the current study was to explore gender differences in North- and South Tyrolian children with regard to the effects of corona pandemic measures on their threat experience, anxiety, and trauma symptoms at three measurement time points (March 2020, December 2020, June 2021). In addition, we explored and compared the children's self-reports with those of parents' estimations of children's mental health problems. We found that both, children and parents reported about decreased mental health in children across the three measurement time points. 
Consistent with recent research on the effects of Covid-19 measures on children (e.g., 30), our study shows that children's mental health problems increased from one measurement point to the next. Similarly, the Co-SPACE study, which tracked the mental health of British children aged 4-16 throughout the corona crisis also found a sharp increase of behavioural, emotional and attentional difficulties in June 2020 and February 2021, when restrictions were the highest (61). Moreover, the authors reported that younger children (aged 4-10) had greater changes in levels of behavioural, emotional and attentional difficulties throughout the pandemic than older children aged 11-16 (ibid.).

Against our assumption, children of the current study did not show any gender differences in self-reported threat experience, anxiety and trauma symptoms. Even though studies have shown contradictory results concerning gender differences in child self-reported PTSD symptoms (e.g., 62), findings of meta-analyses indicated that female gender is a risk factor for the development of PTSD (e.g., 31, 63). The lack of gender differences in our sample could be due to the relative young age of the children as Angold et al. (64) argued that gender differences in internalising symptoms typically emerge during puberty. Our assumption that parents would rate the girls' and boys' threat experience, anxiety and trauma symptoms to a similar extent from their point of view was confirmed for all measurement time points. This finding is in agreement with Shum et al.'s (61) Co-SPACE study results, which showed that parents' estimations of children's symptoms were relatively similar for boys and girls over time.

Our expectations that parents have a misconception about girls' and boys' mental health problems compared to girls' and boys' self-assessments could only be partially confirmed. With regard to the girls' and boys' self-reported threat experiences compared to the parents' estimations, it was shown that parents correctly assessed both, girls' and boys' experiences of threat. It can be assumed that this successful assessment by the parents can be attributed to the fact that the corona pandemic affected the entire population worldwide and was therefore on everyone's lips. The containment measures, which affected everyone more or less equally, and the discussions about the crisis may have led to a better mutual understanding - in the sense of how everyone is doing. Additionally, Chaplin and Aldao (46) found in their meta-analysis that gender differences in children's emotion expression were less pronounced in interaction with parents. That means children felt free to express their emotions in interaction with their parents also if not consistent with gender-stereotypes.

Interestingly, with regard to trauma, the results showed that parents underestimated girls' trauma symptoms compared to girls' self-assessments at all measurement points. They also underestimated boys' trauma symptoms compared to their self-assessments, but not at the first measurement point. Starting with girls, from the perspective of socio-constructivist and socio-developmental gender theory, the parents' misconception could be attributed to the fact that girls are expected to internalise emotions. Internalising emotions facilitate rather than threaten relationships (65). Ellemers (44) reviewed evidence on the content und nature of gender stereotypes and found that implicit impact of gender stereotypes is clearly shown in scholarly work, for example it is assumed that women prioritise family and men work or in other words, women are associated with the private sphere while men dominate the public sphere (66). In this sense, and as also discussed by Berasategi Sancho and colleagues (67) girls might be expected to 
be more involved in in-door activities and thus experience less distress from lockdown measurements. From the second measurement time point onwards, boys also reported increased trauma symptoms in their self-assessment, which means that they escaped the correct assessment of their parents. On the one hand internalising behaviour is of a subjective nature and not easily accessible to others, e.g. parents) $(41,46)$. On the other hand, it is an untypical and unexpected behaviour for boys (46) and thus misjudged by parents.

Limitations of the study include the fact that our sample was opportunistic and not representative. That means we do not know how many children and parents chose not to participate in the study. The recruitment approach might have attracted children and parents who are already engaged and relied on internet access. The findings cannot be extrapolated to the population as a whole. Furthermore, the assessments of parents and children are not directly matched. In addition to assessing mental health problems of the children, it would have been desirable to also assess parents' mental health. Scholarly literature shows that parents' own symptomatology is strongly linked to how they estimate their children's symptoms (68). Furthermore, the retrospective assessment of mental health problems ( $\mathrm{t} 1$ ) could have led to a distorted perception of symptoms by both, parents and children, as the strictest lockdown (March 2020) was followed by relaxations in June 2020 when the measurement time point took place. It should also be mentioned that the threat experience was assessed with newly, not yet psychometrically validated items.

\subsection{Conclusion}

In conclusion, our results do not provide a clear and strong picture of gender differences due to Covid-19related containment measures. Nevertheless, the findings suggest that the parents' misconceptions of girls' and boys' trauma symptoms can be attributed to socio-constructionist and socio-developmental gender theories. Given that past research shows that conservatism might enable individuals to manage feelings of threat and anxiety that environmental uncertainty evokes, future research should explore the socialisation of girls and boys through their parents during times of crisis. The Covid-19 crisis might have reinforced traditional gender roles and adherence to gender stereotypes as shown in the study of Rosenfeld and Tomiyama (69) with U.S. adults before and during the pandemic. The question of whether parents change their socialisation strategy with regard to conservatism and its impact on children should be investigated.

\section{Abbreviations}

CATS

Child and Adolescent Trauma Screen - Self Report

CBCL

Child Behavior Checklist

COPSY-study

impact of Covid-19 on psychological health

Page 13/21 
Covid-19

coronavirus disease

ibid.

ibidem

KAT-III

Kinder-Angst-Test-III

PTSD

Posttraumatic Stress Disorder

SARS

Severe Acute Respiratory Syndrome

WHO

World Health Organization

\section{Declarations}

\subsection{Ethics approval and consent to participate}

Ethics approval was gained by the "Ethics committee of the Medical University of Innsbruck", (No.: 1183/2020). The ethical vote of the Medical University of Innsbruck is valid for the German-speaking population of South Tyrol. This was clarified verbally with the president of the South Tyrolean Ethics Committee. All procedures performed in this study involving human participants were in accordance with the ethical standards of the institutional research committee and with the 1964 Helsinki declaration and its later amendments or comparable ethical standards. Informed consent was obtained from all individual participants included in the study. Parents gave informed consent for their own participation and for children's participation after the objective of the study had been fully explained. A child-friendly version of consent was prepared to obtain consent from children.

\subsection{Consent for publication}

All participants were informed that the results of this study would be published in one or more publications. Children were informed in a child-friendly way. The paper contains no individually identifiable data.

\subsection{Availability of data material}

Data is not available for online access, however readers who wish to gain access to the data can write to the first author Silvia Exenberger at silvia.exenberger-vanham@i-med.ac.at with their requests, which would be subject to ethical approval.

\subsection{Competing interests}

The authors declare that they have no conflicts of interest. 


\subsection{Funding}

The research leading to these results has received funding from the Office of the Tyrolean Government under the project name "Covid-19 Forschung, Folgen Covid-19 Kinder \& Jugendliche" [Covid-19 Research, Impact Covid-19 Children \& Adolescents].

\subsection{Authors' contributions}

SE, SK, NHS, and CT designed the study and worked out the funding application. NHS and CT prepared the study for online use. SE, CT, NHS, SK \& AW recruited the participants. SE and AW drafted the manuscript. MS performed the statistical analyses and gave advise in interpreting the data. SE, BJ, SK interpreted the data. HS gave advise in interpreting the data through a gender lens and developed with SE a gender framework. SE was principal investigator of the study and was main responsible for the planning and design of the study. All authors contributed to and have approved the final manuscript. All authors have agreed both to be personally accountable for the author's own contributions and they ensured that questions related to the accuracy or integrity of any part of the work, even ones in which the author was not personally involved, are appropriately investigated, resolved, and the resolution documented in the literature.

\subsection{Acknowledgements}

We want to thank all parents and children who participated in this study.

\section{References}

1. World Health Organization. WHO Director-General's opening remarks at the media briefing on COVID19 - 11 March 2020. https://www.who.int/director-general/speeches/detail/who-director-general-sopening-remarks-at-the-media-briefing-on-covid-19-11-march-2020 (2020). Accessed 30 Nov 2021.

2. Pollak M, Kowarz N, Partheymüller J. Chronologie zur Corona-Krise in Österreich - Teil 1: Vorgeschichte, der Weg in den Lockdown, die akute Phase und wirtschaftliche Folgen. https://viecer.univie.ac.at/corona-blog/corona-blog-beitraege/blog51/ (2020). Accessed 30 Nov 2021.

3. Ministero Della Salute. Decreto del presidente del consiglio dei ministri 04 marzo 2020. Retrieved from Decreto del presidente del consiglio dei ministri 04 marzo 2020. https://www.governo.it/sites/new.governo.it/files/DPCM4MARZO2020.pdf (2020). Accessed 30 Nov 2021.

4. Ministero Della Salute. Coronavirus, nuovo decreto "\#iorestoacasa" estende a tutta Italia limitazioni aree più colpite. https://www.salute.gov.it/portale/nuovocoronavirus/dettaglioNotizieNuovoCoronavirus.jsp? lingua $=$ italiano\&menu=notizie\& $p=$ dalministero\&id=4184 (2020). Accessed 30 Nov 2021. 
5. Pollak M, Kowarz N, Partheymüller J. Chronologie zur Corona-Krise in Österreich - Teil 2: Von den ersten Lockerungen hinzu einer Normalisierung des öffentlichen Lebens. https://viecer.univie.ac.at/corona-blog/corona-blog-beitraege/blog60/ (2020). Accessed 30 Nov 2021.

6. Ritchie H, Mathieu E, Rodés-Guirao L, Appel C, Giattino C, Ortiz-Ospina E, et al. Italy: Coronavirus Pandemic Country Profile. https://ourworldindata.org/coronavirus/country/italy (2021). Accessed 30 Nov 2021.

7. Pollak M, Kowarz N, Partheymüller J. Chronologie zur Corona-Krise in Österreich - Teil 4: Erneute Lockdowns, Massentests und der Beginn der Impfkampagne. https://viecer.univie.ac.at/coronablog/corona-blog-beitraege/blog100/ (2021). Accessed 30 Nov 2021.

8. II Giorno. Covid, un anno fa il primo lockdown: tutte le tappe. https://www.ilgiorno.it/cronaca/lockdown-1.6111968 (2021). Accessed 30 Nov 2021.

9. The Organisation for Economic Co-operation and Development. The state of school education. One year into the COVID pandemic. Preliminary results - March 2021. https://read.oecdilibrary.org/education/the-state-of-school-education_201dde84-en\#page2 (2021). Accessed 30 Nov 2021.

10. Pollak M, Kowarz N, Partheymüller J. Chronologie zur Corona-Krise in Österreich - Teil 5: Dritte Welle, regionale Lockdowns und Impffortschritt. https://viecer.univie.ac.at/corona-blog/corona-blogbeitraege/blog112/ (2021). Accessed 30 Nov 2021.

11. Statistica. Entwicklung der Coronavirus-Epidemie (COVID-19) im Bundesland Tirol seit Februar 2020. https://de.statista.com/statistik/daten/studie/1114903/umfrage/entwicklung-der-fallzahlen-descoronavirus-in-tirol/ (2021). Accessed 30 Nov 2021.

12. Autonome Provinz Bozen - Südtirol. Aktuelle Daten zum Coronaviru. https://www.provinz.bz.it/sicherheit-zivilschutz/zivilschutz/aktuelle-daten-zum-coronavirus.asp (2021). Accessed 30 Nov 2021.

13. Panchal U, Salazar de Pablo G, Franco M, Moreno C, Parellada M, Arango C, et al. The impact of COVID-19 lockdown on child and adolescent mental health: systematic review. European Child Adolescent Psychiatry. 2021. doi:10.1007/s00787-021-01856-w.

14. Racine N, McArthur BA, Cooke JE, Eirich R, Zhu J, Madigan S. Global Prevalence of Depressive and Anxiety Symptoms in Children and Adolescents During COVID-19: A Meta-analysis. JAMA pediatrics. 2021. doi:10.1001/jamapediatrics.2021.2482.

15. Samji H, Wu J, Ladak A, Vossen C, Stewart E, Dove N, et al. Review: Mental health impacts of the COVID-19 pandemic on children and youth - a systematic review. Child Adolesc Mental Health. 2021. doi:10.1111/camh.12501.

16. Fong VC, larocci G. Child and Family Outcomes Following Pandemics: A Systematic Review and Recommendations on COVID-19 Policies. J Pediatr Psychol. 2020. doi:10.1093/jpepsy/jsaa092.

17. Ma L, Mazidi M, Li K, Li Y, Chen S, Kirwan R, et al. Prevalence of mental health problems among children and adolescents during the COVID-19 pandemic: A systematic review and meta-analysis. J 
Affect Disord. 2021. doi:10.1016/j.jad.2021.06.021.

18. Luijten MAJ, van Muilekom MM, Teela L, Polderman TJC, Terwee CB, Zijlmans J, et al. The impact of lockdown during the COVID-19 pandemic on mental and social health of children and adolescents. Quality of life research: an international journal of quality of life aspects of treatment care rehabilitation. 2021. doi:10.1007/s11136-021-02861-x.

19. Pereira Al, Muris P, Roberto MS, Stallard P, Garcia-Lopez LJ, Tulbure BT, et al. Cumulative Risk Exposure and Social Isolation as Correlates of Carer and Child Mental Health During the COVID-19 Pandemic: An Online Study with Families from Various Europeans Countries. Child Psychiatry Hum Dev. 2021. doi:10.1007/s10578-021-01233-3.

20. Pizarro-Ruiz JP, Ordóñez-Camblor N. Effects of Covid-19 confinement on the mental health of children and adolescents in Spain. Sci Rep. 2021. doi:10.1038/s41598-021-91299-9.

21. Schmidt SJ, Barblan LP, Lory I, Landolt MA. Age-related effects of the COVID-19 pandemic on mental health of children and adolescents. European journal of psychotraumatology. 2021. doi:10.1080/20008198.2021.1901407.

22. Rothe J, Buse J, Uhlmann A, Bluschke A, Roessner V. Changes in emotions and worries during the Covid-19 pandemic: an online-survey with children and adults with and without mental health conditions. Child Adolesc Psychiatry Mental Health. 2021. doi:10.1186/s13034-021-00363-9.

23. Vogel M, Meigen C, Sobek C, Ober P, Igel U, Körner A, et al. Well-being and COVID-19-related worries of German children and adolescents: A longitudinal study from pre-COVID to the end of lockdown in Spring 2020. JCPP advances. 2021. doi:10.1111/jcv2.12012.

24. Idoiaga Mondragon N, Berasategi Sancho N, Dosil Santamaria M, Eiguren Munitis A. Struggling to breathe: a qualitative study of children's wellbeing during lockdown in Spain. Psychology health. 2021. doi:10.1080/08870446.2020.1804570.

25. O'Sullivan K, Clark S, McGrane A, Rock N, Burke L, Boyle N, et al. A Qualitative Study of Child and Adolescent Mental Health during the COVID-19 Pandemic in Ireland. Int J Environ Res Public Health. 2021. doi:10.3390/ijerph18031062.

26. Segre G, Campi R, Scarpellini F, Clavenna A, Zanetti M, Cartabia M, et al. Interviewing children: the impact of the COVID-19 quarantine on children's perceived psychological distress and changes in routine. BMC Pediatrics. 2021. doi:10.1186/s12887-021-02704-1.

27. Terzioğlu MA, Büber A. Traumatic Effects of the COVID-19 Outbreak in Middle School Students and Caregivers. Psychiatry investigation. 2021;18(6):553-60.

28. Newlove-Delgado T, McManus S, Sadler K, Thandi S, Vizard T, Cartwright C, et al. Child mental health in England before and during the COVID-19 lockdown. The lancet Psychiatry. 2021;8(5):353-4.

29. Ravens-Sieberer U, Kaman A, Erhart M, Devine J, Schlack R, Otto C. Impact of the COVID-19 pandemic on quality of life and mental health in children and adolescents in Germany. Eur Child Adolesc Psychiatry. 2021. doi:10.1007/s00787-021-01726-5.

30. Ravens-Sieberer U, Kaman A, Erhart M, Otto C, Devine J, Löffler C, et al. Quality of life and mental health in children and adolescents during the first year of the COVID-19 pandemic: results of a two- 
wave nationwide population-based study. Eur Child Adolesc Psychiatry. 2021. doi:10.1007/s00787021-01889-1.

31. Alisic E, Zalta AK, van Wesel F, Larsen SE, Hafstad GS, Hassanpour K, et al. Rates of post-traumatic stress disorder in trauma-exposed children and adolescents: meta-analysis. The British journal of psychiatry: the journal of mental science. 2014. doi:10.1192/bjp.bp.113.131227.

32. Trickey D, Siddaway AP, Meiser-Stedman R, Serpell L, Field AP. A meta-analysis of risk factors for post-traumatic stress disorder in children and adolescents. Clin Psychol Rev. 2012; doi:10.1016/j.cpr.2011.12.001+.

33. Lau JTF, Yang X, Pang E, Tsui HY, Wong E, Wing YK. SARS-related perceptions in Hong Kong. Emerg Infect Dis. 2005. doi:10.3201/eid1103.040675.

34. Sprang G, Silman M. Posttraumatic stress disorder in parents and youth after health-related disasters. Disaster Med Pub Health Prep. 2013. doi:10.1017/dmp.2013.22.

35. Wang $Y, X u B$, Zhao G, Cao R, He X, Fu S. Is quarantine related to immediate negative psychological consequences during the 2009 H1N1 epidemic? General hospital psychiatry. 2011; doi:10.1016/j.genhosppsych.2010.11.001.

36. Buzzi C, Tucci M, Ciprandi R, Brambilla I, Caimmi S, Ciprandi G, et al. The psycho-social effects of COVID-19 on Italian adolescents' attitudes and behaviors. Italian Journal of Pediatrics. 2020. doi:10.1186/s13052-020-00833-4.

37. Gotlib IH, Borchers LR, Chahal R, Gifuni AJ, Teresi GI, Ho TC. Early Life Stress Predicts Depressive Symptoms in Adolescents During the COVID-19 Pandemic: The Mediating Role of Perceived Stress. Frontiers in psychology. 2020. doi:10.3389/fpsyg.2020.603748.

38. Scheeringa MS, Wright MJ, Hunt JP, Zeanah $\mathrm{CH}$. Factors affecting the diagnosis and prediction of PTSD symptomatology in children and adolescents. Am J Psychiatry. 2006. doi:10.1176/ajp.2006.163.4.644.

39. De Los Reyes A, Augenstein TM, Wang M, Thomas SA, Drabick DAG, Burgers DE, et al. The validity of the multi-informant approach to assessing child and adolescent mental health. Psychological bulletin. 2015. doi:10.1037/a0038498.

40. Cremeens J, Eiser C, Blades M. Factors influencing agreement between child self-report and parent proxy-reports on the Pediatric Quality of Life Inventory 4.0 (PedsQL) generic core scales. Health Qual Life Outcomes. 2006. doi:10.1186/1477-7525-4-58.

41. Grills $A E$, Ollendick TH. Issues in parent-child agreement: the case of structured diagnostic interviews. Clin Child Fam Psychol Rev. 2002. doi:10.1023/a:1014573708569.

42. Popp L, Neuschwander M, Mannstadt S, In-Albon T, Schneider S. Parent-Child Diagnostic Agreement on Anxiety Symptoms with a Structured Diagnostic Interview for Mental Disorders in Children. Frontiers in psychology. 2017. doi:10.3389/fpsyg.2017.00404.

43. West C, Zimmerman DH. Doing Gender. Gender Society. 1987. doi:10.1177/0891243287001002002.

44. Ellemers N. Gender Stereotypes. Annu Rev Psychol. 2018. doi:10.1146/annurev-psych-122216011719. 
45. Brody LR, Hall JA. Gender and emotion in context. In: Lewis M, Haviland-Jones JM, Barrett LF, editors. Handbook of emotions. New York: The Guilford Press; 2008. pp. 395-408.

46. Chaplin TM, Aldao A. Gender differences in emotion expression in children: a meta-analytic review. Psychological bulletin. 2013. doi:10.1037/a0030737.

47. Raffeiner A. Der Erste Weltkrieg und seine Folgen für das Zusammenleben der Völker in Mittel- und Ostmitteleuropa, Teil 2. In: Gornig GH, Michel AA, editors. Die Südtirol-Frage. Berlin: Duncker \& Humblot; 2019. pp. 154-67.

48. Choffy SC. The Problem of the South Tyrol. World Affairs. 1961;124:47-9.

49. Raffeiner A. Südtirol spricht immer noch Deutsch. Ein Streifzug durch die Geschichte eines begehrten Landes - Teil 1: bis 1945. Deutsche Sprachwelt: Die Plattform für alle, die Sprache lieben. 2010; 41: 5.

50. Autonomous Province of South Tyrol - Provincial Statistics Institute. South Tyrol in figures - 2020 https://astat.provinz.bz.it/downloads/Siz_2020-eng.pdf (2020). Accessed 30 Nov 2021.

51. Tirol L. Verordnung Nr. 128 der Bezirkshauptmannschaft Landeck: Verkehrsbeschränkende Maßnahmen nach dem Epidemiegesetz 1950 für die Gemeinden im Paznauntal und Gemeinde St. Anton a. A. https://www.tirol.gv.at/fileadmin/buergerservice/bote/downloads/2020/Bote_10b2020.pdf (2020). Accessed 30 Nov 2021.

52. Melotti R, Scaggiante F, Falciani M, Weichenberger CX, Foco L, Lombardo S, et al. Prevalence and determinants of serum antibodies to SARS-CoV-2 in the general population of the Gardena Valley. 2021; doi:10.1101/2021.03.19.21253883.

53. Sachser C, Berliner L, Holt T, Jensen TK, Jungbluth N, Risch E, et al. International development and psychometric properties of the Child and Adolescent Trauma Screen (CATS). J Affect Disord. 2017. doi:10.1016/j.jad.2016.12.040.

54. Tewes A, Naumann A. KAT-III Kinder-Angst-Test-III. Göttingen: Hogrefe; 2016.

55. Döpfner M, Plück J, Kinnen C, ArbeitsgruppeDeutscheChildBehaviorChecklist.. CBCL/6-18R, TRF/618R, YSR/11-18R: Deutsche Schulalter-Formen der Child Behavior Checklist von Thomas M. Achenbach. Göttingen: Hogrefe; 2014.

56. Walter R, Remschmidt H. Untersuchungen zur Reliabilität, Validität und Faktorenstruktur einer deutschsprachigen Version der Child Behavior Checklist. Zeitschrift für Klinische Psychologie. 1999. doi:10.1026//0084-5345.28.3.177.

57. Lime Survey GmbH. Lime Survey: an open source survey tool. https://www.limesurvey.org (2021). Accessed 30 Nov 2021.

58. ESD: ESD. https://ches.pro/. (2020). Accessed 30 Nov 2021.

59. Tirol L. Verordnung Nr. 155 der Bezirkshauptmannschaft Imst: Verkehrsbeschränkende Maßnahmen für die Gemeinde Sölden nach dem Epidemiegesetz 1950. https://www.tirol.gv.at/fileadmin/buergerservice/bote/downloads/2020/Bote_11a-2020.pdf (2020). Accessed 30 Nov 2021.

60. Cohen J. Statistical Power Analysis for the Behavioral Sciences. Hillsdale: Erlbaum; 1988. 
61. Shum A, Skripkauskaite S, Pearcey S, Raw J, Waite P, Creswel C. Report 07: Changes in parents' mental health symptoms and stressors from April to December 2020. https://cospaceoxford.org/wpcontent/uploads/2021/01/Report_07_19JAN.pdf (2020). Accessed 30 Nov 2021.

62. Soysa CK. War and Tsunami PTSD Responses in Sri Lankan Children: Primacy of Reexperiencing and Arousal Compared to Avoidance-Numbing. Journal of Aggression Maltreatment Trauma. 2013. doi:10.1080/10926771.2013.824056.

63. Tang B, Deng Q, Glik D, Dong J, Zhang L. A Meta-Analysis of Risk Factors for Post-Traumatic Stress Disorder (PTSD) in Adults and Children after Earthquakes. Int J Environ Res Public Health. 2017. doi:10.3390/ijerph14121537.

64. Angold A, Worthman C, Costello EJ. Puberty and depression. In: Hayward C, editor. Gender differences at puberty. New York: Cambridge University Press; 2003. pp. 137-64.

65. Izard CE, Ackerman B. Motivational, organizational, and regulatory functions of discrete emotions. In: Lewis M, Haviland-Jones JM, editors. Handbook of Emotions. New York: The Guilford Press; 2000. pp. 253-64.

66. Dildar Y. Patriarchal Norms, Religion, and Female Labor Supply: Evidence from Turkey. World Dev. 2015. doi:10.1016/j.worlddev.2015.06.010.

67. Berasategi Sancho N, Idoiaga Mondragon N, Dosil Santamaria M, Eiguren Munitis A. The Well-being of children in lock-down: Physical, emotional, social and academic impact. Child Youth Serv Rev. 2021. doi:10.1016/j.childyouth.2021.106085.

68. Exenberger S, Riedl D, Rangaramanujam K, Amirtharaj V, Juen F. A cross-sectional study of motherchild agreement on PTSD symptoms in a south Indian post-tsunami sample. BMC Psychiatry. 2019. doi:10.1186/s12888-019-2408-9.

69. Rosenfeld D, Tomiyama AJ. Can a Pandemic Make People More Socially Conservative? Longitudinal Evidence from COVID-19. J Appl Soc Psychol. 2021. doi:10.1111/jasp.12745.

\section{Figures}


Figure 1

Children's threat experiences, anxiety and trauma symptoms from their own perspectives and parents' point of view
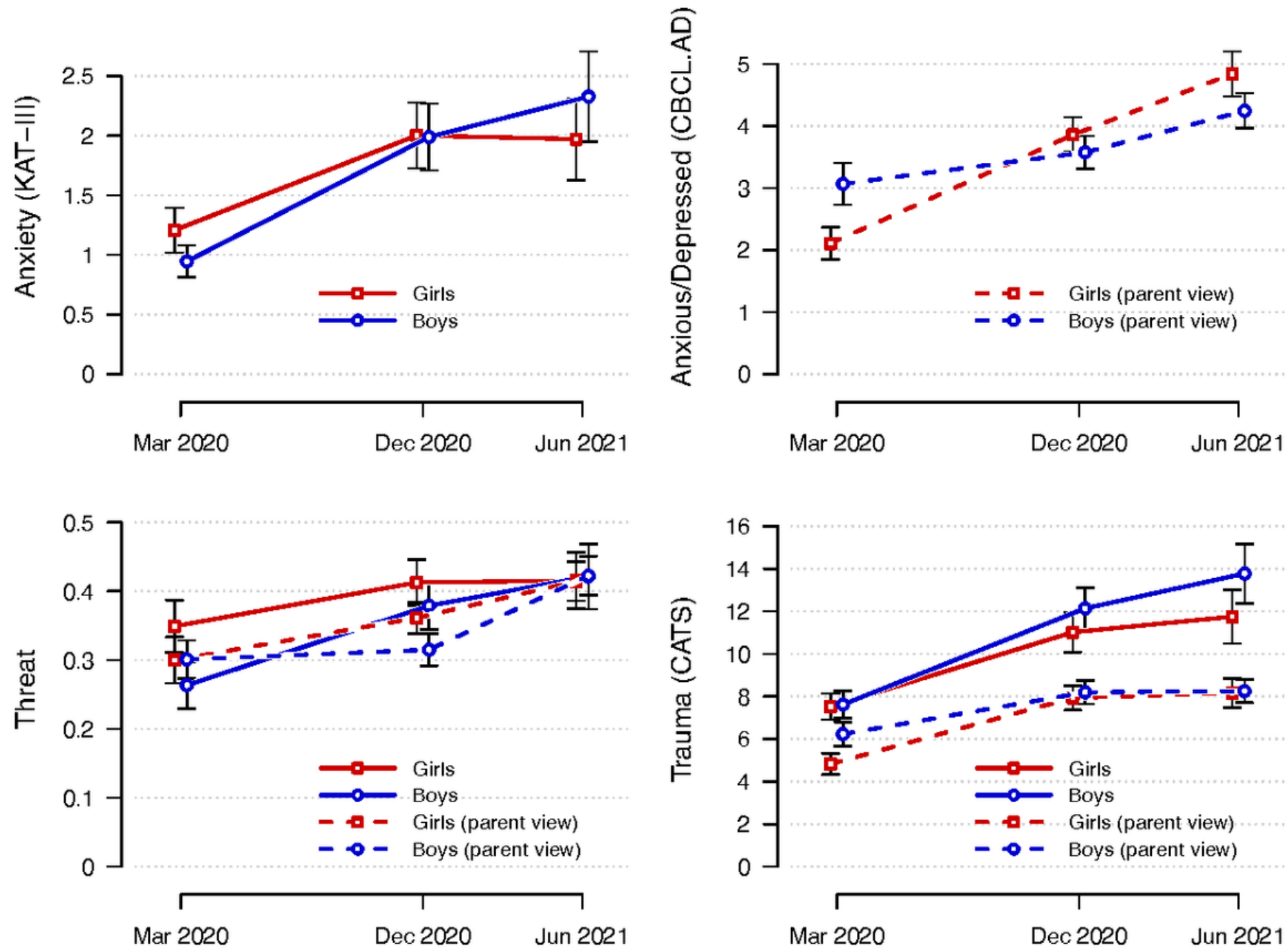

Note. Error bars show standard errors of mean (SEM).

\section{Figure 1}

Children's threat experiences, anxiety and trauma symptoms from their own perspectives and parents' point of view. 